\title{
Gaya Komunikasi Kepala Madrasah Terhadap Peningkatan Kinerja Guru Di MTs Al Huda Pangkalan Susu Kabupaten Langkat
}

\author{
Handoko \\ UIN Sumatera Utara, Medan
}

Corresponding Author handoko098@gmail.com

\begin{tabular}{|c|c|}
\hline & ABSTRACT \\
\hline $\begin{array}{l}\text { ARTICLE INFO } \\
\text { Article history: } \\
\text { Received } \\
\text { 02 January } 2021 \\
\text { Revised } \\
\text { 08 January } 2021 \\
\text { Accepted } \\
\text { 14 Desember } \\
2021\end{array}$ & $\begin{array}{l}\text { This study was conducted to determine how the principal's } \\
\text { communication style towards improving teacher performance. Mts Al } \\
\text { Huda is one of the educational institutions in Langkat district, which is } \\
\text { located at Jl. Kurnia village of Sei Siur Kec. Pangkalan Susu Kab. Leave. } \\
\text { Based on the grand tour that the researchers conducted, Mts Al Huda was } \\
\text { dominated by underprivileged fishermen's children and Mts Al Huda did } \\
\text { not charge education, meaning thats education was held free of charge } \\
\text { and had a growing number of students from year to year. The research } \\
\text { methodology used is a qualitative approach using descriptive methods. } \\
\text { This approach is used to study the problem and get a deep meaning about } \\
\text { the Communication Style of the Head of Madrasah towards increasing } \\
\text { Teacher Performance in Mts Al Huda Kec. Pangkalan Susu Kab. Leave. } \\
\text { The results of the study (1) The communication process that occurred in } \\
\text { Madrasah Tsanawiyah Al Huda Kec. Pangkalan Susu Kab. Langkat is } \\
\text { already running well, Madrasah principals use formal and informal } \\
\text { communication. Where formal communication is used by the head of the } \\
\text { Madrasah in meetings in the form of two-way communication by } \\
\text { expecting opinions and suggestions from the forum in making decisions. } \\
\text { (2) The efforts of the head of Madrasah in improving teacher performance } \\
\text { at Madrasah Tsanawiyah Al Huda Kec. Pangkalan Susu is by paying } \\
\text { attention to the environment, providing motivation so that it makes } \\
\text { teachers feel comfortable in carrying out their duties, while maintaining } \\
\text { discipline so that good performance from teachers can be realized. (3) } \\
\text { communication of the head of Madrasah Tsanawiyah Al Huda Kec. } \\
\text { Pangkalan Susu Kab. Tool in improving teacher performance using The } \\
\text { Equalitarian Style and The Relinguishing Style. These two styles are } \\
\text { interconnected, where the Equalitarian Style has a common ground, } \\
\text { meaning that this communication is two-way, everyone is free to express } \\
\text { their opinions or suggestions. }\end{array}$ \\
\hline Key Word & Communication, Performance, Environment, Principals \\
\hline How to cite & $\begin{array}{l}\text { Handoko, (2021). Gaya Komunikasi Kepala Madrasah Terhadap } \\
\text { Peningkatan Kinerja Guru Di MTs Al Huda Pangkalan Susu } \\
\text { Kabupaten Langkat . Jurnal Journal Of Education And Teaching } \\
\text { Learning (Jetl). }\end{array}$ \\
\hline
\end{tabular}

\section{PENDAHULUAN}

Komunikasi merupakan aktifitas dasar yang selalu dilakukan manusia setiap waktunya. Komunikasi juga merupakan suatu proses yang mempunyai komponen dasar yaitu sumber (the source), pesan (the massage), saluran (the 
channel) dan penerima (the recever). Hal ini merupakan suatu proses komunikasi dalam interaksi manusia dalam kehidupan sehari-hari untuk mendapatkan saling pengertian (feed back).

Pada dasarnya manusia sebagai makhluk sosial sudah pasti melakukan komunikasi dengan manusia lainnya. Hal ini menunjukkan bahwa betapa pentingnya komunikasi dalam kehidupan manusia. Seperti yang diungkapkan oleh seorang pakar komunikasi yaitu Shannon dan Weaver dikutip oleh (Rina Nurahman, 2017) bahwa komunikasi sebagai bentuk interaksi manusia yang saling pengaruh mempengaruhi satu sama lainnya. Sengaja atau tidak disengaja, tidak terbatas pada bentuk komunikasinya baik menggunkan bahasa verbal maupun nonverbal.

Pentingnya komunikasi bagi manusia tidak dapat dipungkiri begitu juga halnya dalam suatu organisasi, apabila tidak ada proses komunikasi, para anggota tidak dapat menerima informasi antar sesama anggota. Koordinasi kerja tidak mungkin dilakukan dan organisasi akan runtuh karena ketiadaan komunikasi. Kerja sama juga menjadi suatu hal yang sangat mustahil, karena orang-orang tidak dapat mengkomunikasikan kebutuhan atau keinginan serta perasaan mereka kepada orang lain. Jadi, peran komunikasi dalam organisasi merupakan hal yang sangat penting untuk mencapai tujuan organisasi.

Keterampilan komunikasi pimpinan dalam sebuah organisasi merupakan salah satu penentu keberhasilan dalam menjalankan kepemimpinannnya di sebuah organisasi, seperti yang diungkap oleh Barnard dan Kuswarno (Suryaningsih, 2009) yaitu, "komunikasi merupakan kekuatan utama dalam membentuk organisasi dan komunikasi membuat dinamis suatu sistem kerja sama dalam organisasi dan menghubugkan tujuan organisasi partisipasi orang di dalamnya".

Kemampuan berkomunikasi dan berinteraksi sangatlah penting dalam suatu kehidupan berorganisasi, bahkan menjadi tuntutan bagi setiap orang yang berada dalam lingkungannya. Kepala madrasah adalah orang yang bertanggungjawab dalam melaksanakan kegiatan pendidikan di sekolah dan melakukan kegiatan dalam usaha mempengaruhi orang lain yang ada dilingkungannya pada situasi tertentu agar orang lain dapat bekerja dengan penuh rasa tanggungjawab demi tercapainya tujuan yang telah di tetapkan. Kepala madrasah adalah orang yang berada di depan guru, karyawan, dan siswa sekolahnya. Kepala madrasah merupakan orang paling utama mempengaruhi para guru serta aktivitas sekolahnya dalam mewujudkan tujuan pendidikan. Kepala madrasah sebagai pusat kekuatan dan dinamisator bagi organisasi mau tidak mau harus mampu berkomunikasi kepada semua pihak, baik secara formal dan informal. 
Gaya komunikasi yang sukses pada umumnya menggunkan gaya komunikasi yang tegas dalam kegiatan sehari-hari juga dalam memimpin sebuah organisasi. Pimpinan pada umumnya memiliki kemampuan untuk melakukan komunikasi yang efektif, sehingga mampu merangsang partisipasi orang-orang yang di pimpinnya. Seorang pimpinan akan memiliki sekumpulan gaya yang digunakan untuk mempengaruhi bawaha agar sasaran organisasi tercapai.

Kinerja adalah hasil yang diperolah oleh seseorang dalam melaksanakan pekerjaannya. Lebih jauh Indara Bastian menyatakan (Fahmi, 2015) bahwa kinerja adalah gambaran mengenai tingkat pencapaian pelaksanaan suatu kegiatan, program, atau kebijaksanaan dalam mewujudkan sasaran, tujuan, misi dan visi organisasi yang tertuang dalam perumusan skema strategis (strategic planning) suatu organisasi.

Melalui gaya komunikasi pimpinan inilah seorang kepala madrasah akan mampu mempengaruhi para guru untuk mempertahankan dan meningkatkan kinerja dalam mewujudkan visi, misi, serta sasaran sekolahnya. Kepala Madrasah bertanggung jawab terhadap kelancaran pelaksanaan pendidikan dan pengajaran di sekolah yang ia pimpin. Untuk melaksanakan tugasnya dengan baik, kepala madrasah hendaknya memahami, menguasai dan mampu melaksanakan kegiatan-kegiatan yang berkenaan dengan tugasnya sebagai manajer pendidikan. Kepala Madrasah merupakan orang yang berada pada garis terdepan dalam mengkoordinasikan berbagai usaha dalam meningkatkan kinerja guru yang bermutu.

Guru memegang peranan dalam meningkatkan mutu pendidikan, maka perhatian terhadap peningkatan kinerja guru menjadi penting. Dengan berbagai perkembangan ilmu pengetahuan teknologi, seseorang guru di tuntut untuk mampu mengadaptasikan dirinya supaya ilmu dan keterampilan yang di transfer kepada peserta didik tidak ketinggalan oleh perkembangan ilmu itu sendiri. Maka dari itu tugas guru tidak hanya sebagai pendidik tetapi juga mengajar, dan melatih. Kedudukan guru seperti ini menunjukkan bahwa mengajar merupakan mekanisme untuk pengembangan kecakapan intelektual dalam organisasi.

Guru yang memiliki kinerja yang tinggi harus terus berusaha meningkatkan kompetensinya dalam perencanaan pembelajaran, pelaksanaan, maupun penilaian pembelajaran sehingga diperoleh hasil kerja yang optimal. Hal tersebut menunjukkan bahwa dalam proses belajar mengajar, guru bertindak sebagai organisator, pengelola dan fasilitator.

Hal ini tidak akan terwujud tanpa adanya komunikasi yang baik antara guru dan kepala Madrasah, kerena komunikasi adalah urut nadi suatu 
organisasi. Salah satu faktor penentu bagi keberhasilan organisasi yaitu gaya komunikasi pimpinan, dimana harus tercipta komunikasi yang efektif antara pimpinan dan bawahan. Kepala madrasah harus membangun komunikasi yang baik dan efektif untuk menjalankan roda kepemimpinan di sekolah yang ia pimpin. Menurut (Jalaluddin, 2008) dalam bukunya Psikologi Komunikasi ia menyebutkan komunikasi yang efektif ditandai dengan adanya pengertian, dapat menimbulkan kesenangan, mempengaruhi sikap, meningkatkan hubungan sosial yang baik, dan pada akhirnya menimbulkan suatu tindakan.

Komunikasi yang terjadi di sekolah, terutama antara kepala sekolah dengan guru, jika dilakukan secara baik dan intensif maka akan mempengaruhi sikap guru dalam mengemban tugasnya sehari-hari, yang berujung pada terjadinya peningkatan kinerja guru di sekolah. Sebaliknya, apabila proses interaksi komunikasi yang terjadi di sekolah kurang baik, maka akan melahirkan sikap yang apatis. Hal ini terjadi di MTs Al Huda yakni hubungan kepala sekolah, guru dan siswa kurang erat dikarenakan terbatasnya alat belajar siswa sebab sebahagian besar mereka berasal dari background keluarga yang kurang mampu serta kondisi interaksi social di masa pandemic Covid-19 saat ini, yang mana penerapan social distancing menjadikan sebab tidak sampainya pesan yang diberikan kepala sekolah meskipun dengan gaya komunikasi yang baik. Jika ini terjadi maka akan berdampak pada peningkatan kinerja guru.

Mts Al Huda merupakan salah satu lembaga pendidikan yang ada di kabupaten Langkat, yang beralamatkan di Jl. Kurnia desa Sei Siur Kec. Pangkalan Susu Kab. Langkat. Berdasarkan grand tour yang peneliti lakukan bahwa, Mts Al Huda didominasi oleh anak-anak nelayan yang kurang mampu dan Mts Al Huda tidak ada mengenakan biaya pendidikan artinya pendidikan diselenggarakan secara gratis serta memiliki jumlah siswa yang terus meningkat dari tahun ke tahun. Masa pandemic Covid-19 saat ini meskipun siswa baru ada peningkatan namun disisi lain berdampak terhadap turunnya minat belajar siswa, disebabkan keadaan orangtua mereka yang kurang peduli terhadap kemajuan pendidikan anak-anaknya. Dikarenakan hal demikianlah peneliti tertarik untuk meneliti di tempat tersebut. Namun demikian, untuk membatasi ruang lingkup penelitian yang dilakukan oleh peneliti, dan terbatasannya waktu maka peneliti memfokuskan pada Madrasah Tsanawiyah (MTs). Alasannya Madrasah Tsanawiyah ini sudah berakreditasi B. Peneliti ingin mengetahui bagaimana gaya komunikasi kepala madrasah terhadap peningkatan kinerja guru. 


\section{METODOLOGI PENELITIAN}

Penelitian ini menggunakan pendekatan kualitatif dengan menggunakan metode deskriptif. Pendekatan ini digunakan untuk mengkaji permasalahan dan memperoleh makna secara mendalam tentang Gaya Komunikasi Kepala Madrasah terhadap peningkatan Kinerja Guru di Mts Al Huda Kec. Pangkalan Susu Kab. Langkat. Penelitian kualitatif dalam pandangan (Sugiono 2012, hlm. 77) adalah gejala itu bersifat holistic (menyeluruh, tidak dapat dipisahpisahkan), sehingga peneliti kualitatif tidak akan menetapkan penelitiaanya hanya berdasarkan variabel penelitian, tetapi keseluruhan situasi sosial yang diteliti yang meliputi aspek tempat (place), pelaku (actor), dan aktivitas (activity) yang berinteraksi secara sinergis.

\section{HASIL DAN PEMBAHASAN}

Gaya Komunikasi Kepala Madrasah Dalam Meningkatkan Kinerja Guru di Madrasah Tsanawiyah Al Huda Kec. Pangkalan Susu Kab. Langkat

Setiap orang mempunyai gaya komunikasi yang bersifat personal, yang merupakan gaya khas seseorang didalamberkomunikasi. Sehingga gaya komunikasi dapat dikatakan sebagai suatu kepribadian yang terdapat didalam diri setiap manusia yang sukar untuk diubah. Untuk memahami gaya berkomunikasi maka setiap orang harus berusaha menciptakan dan memperhatikan gaya komunikasi personal sebagai ciri khas pribadinya (Rina Nurahman, 2017).

Kepala Madrasah Tsanawiyah Yayasan Nurorrodhiyah Kota Jambi gaya komuniksi yang digunakan dalam meningkatkan kinerja guru menggunakan komunikasi dua arah, dimana selalu mengharapkan saran dan pendapat dari guru. Termasuk dalam mengambil keputusan kepala Madrasah dalam meningkatkan kinerja guru tidak hanya menggunakan satu gaya komunikasi, ada dua gaya komunikasi yang di kombinasikan yaitu sebagai berikut:

1. The Equalitarian Style yaitu komunikasi dua arah, dimana kepala Madrasah Tsanawiyah Nururrodhiyah dalam berkomunikasi dengan guru selalu memberi kesempatan untuk menyampaikan saran atau pendapat.

2. The Relinguishing Style, gaya komunikasi ini lebih mencerminkan kesedian menerima saran, pendapat ataupun gagasan prang lain, dari pada keinginan perintah, meskipun kepala madrasah mempunyai hak untuk memberi perintah. 


\section{Upaya Peningkatan Kinerja Guru Oleh Kepala Madrasah Tsanawiyah Al Huda Kec. Pangkalan Susu}

Dalam upaya mewujudkan kinerja yang baik diperlukan proses penilaian kinerja. Fatimah dkk (Barnawi dan Arifin, 2012) mengemukakan bahwa "penilaian kinerja merupakan suatu kegiatan guna menilai perilaku pegawai dalam pekerjaannya, baik secara kualitatif maupun kuantitatif". Kinerja guru sangat dipengaruhi oleh lingkungan, perilaku, jabatan, penilaian, administrasi, dan karakteristik individu yang terdiri atas pengetahuan, keterampilan, kemampuan, motivasi, kepercayaan, nilai-nilai serta sikap dalam meningkatkan kinerja guru kepala Madrasah sangat disiplin contohnya apabila lonceng masuk telah di bunyikan kepala Madrasah sering berkeliling ke kelas mengecek apakah guru telah melaksanakan proses pembelajaran, apabilah ditemukan masih ada kelas yang belum ada gurunya maka disuruhlah ketua kelas untuk memanggil guru tersebut dan apabila guru tersebut berhalangan masuk maka guru piketlah yang akan menggantikannya.

Kepala Madrasah juga memberi motivasi kepada guru untuk meningkatkan kinerja, Dalam peningkatan kinerja guru, kepala Madrasah juga memperhatikan kebutuhan dasar guru. Seperti yang dikatakan Abraham H. Maslow bahwa kebutuhan dasar manusia yaitu:

1. Kebutuhan fisik (lapar dan haus)

2. Kebutuhan akan rasa aman

3. Kebutuhan sosial (persahabatan dan kekerabatan)

4. Kebutuhan akan penghargaan (prestise)

5. Kebutuhan untuk mewujudkan diri (aktualisasi diri)

Tidak hanya itu, kepala Madrasah juga menerapkan fungsi- fungsi manajemen. Menurut Malayu P. Hasibuan, dalam buku (Kompri, 2015, hlm. 17) kegiatan-kegiatan dalam fungsi manajemen yaitu sebagai berikut:

\section{Perencanaan (Planning)}

Perencanan ini meliputi penetapan tujuan dan merumuskan strategi untuk mencapai tujuan yang telah di tetapkan, hal ini dilakukan kepala Madrasah pada rapat awal semester yang mana rapat ini diikuti oleh seluruh guru serta staf sekolah.

2. Pengorganisasian (Organizing)

Pengorganisasian adalah mengalokasikan sumber daya, merumuskan dan menetapkan tugas, dan menetapkan prosedur yang diperlukan seperti menetapkan struktur organisasi, pembagaian wali kelas, yang menunjukkan adanya wewenang dan tanggung jawab. 


\section{c. Mengimplementasikan (Directing)}

Mengimplementasikan merupakan proses kepemimpinan, pembimbingan, dan pemberian motivasi kepada guru agar dapat bekerja secara efektif dan efisien dalam pencapaiaan tujuan serta memberikan tugas dan penjelasan rutin mengenai kebijakan yang telah di tetapkan.

d. Pengawasan (Controlling)

Mengevaluasi keberhasilan dalam pencapaiaan tujuan dan target sesuai dengan indikator yang telah di tetapkan, ini dilakukan pada rapat akhir semester, sama seperti rapat awal semester.

\section{Proses Komunikasi Kepala Madrasah Tsanawiyah Al Huda Kec.Pangkalan Susu di masa pandemic Covid-19}

Komunikasi merupakan sesuatu yang sangat pokok dalam setiap hubungan orang-orang, begutu pula dalam sebuah organisasi terjadinya komunikasi tentu ada tujuan yang ingin dicapai. Hal ini tidak akan terlepas dari bagaimana proses komunikasinya. Komunikasi di sekolah itu sangat besar peranan atau manfaatnya menyampaikan pesan yaitu kepala Madrasah kepada guru dan guru dapat melaksanakan informasi itu kepada anak didik. Disiplin mengarah pada kegiatan yang mendidik guru untuk patuh terhadap aturanaturan madrasah. Bentuk disiplin guru yaitu kehadiran tepan waktu, mengajar sesuai dengan perencanaan pembelajaran seperti rincian minggu efektif, RPP, program tahunan, program semester dan kriteria ketuntasan minimal.

Proses komunikasi merupakan penyampaian pikiran atau perasaan seseorang kepada orang lain. Pikiran bisa berupa gagasan, informasi, opini dan lain-lain yang muncul dari benaknya. Perasaan bisa berupa keyakinan, keraguan, kekhawatiran, kemarahan, keberanian, kegairahan, dan sebagainya yang timbul dari lubuk hati (Rina Nurahman, 2017, hlm. 63). Pada masa pandemi Covid-19 saat ini hampir disetiap sendi interaksi social baik skala kecil maupun berskala besar mengalami hambatan dalam proses komunikasi. Sebab pesan yang disampaikan terkadang menjadi suatu yang tak berkesan antara sesame komunikan.

Kepala Madrasah juga biasanya melakukan pendekatan kepada guru dan stakeholder yang ada yang kurang menerima aturan dan kebijakan yang telah ditetapkan dengan melakukan komunikasi mendalam yaitu dengan mengajaknya bercerita, terkadang kepala Madrasah mengajak cerita di dalam ruangannya atau ketika pada saat guru tersebut sedang berada sendirian di 
ruang guru. Selain itu kepala Madrasah juga berkomunikasi melalui telepon, grup WhatsApp atau pun melalui surat.

\section{KESIMPULAN}

Berdasarkan temuan khusus dan pembahasan pada bab sebelumnya maka peneliti dapat menyimpulkan hasil penelitian menjadi beberapa hal sebagai berikut:

1. Proses komunikasi yang terjadi di Madrasah Tsanawiyah Al Huda Kec. Pangkalan Susu Kab. Langkat sudah berjalan dengan baik, kepala Madrasah menggunakan komunikasi formal dan informal. Dimana komunikasi formal digunakan kepala Madrasah ketika rapat yang berbentuk komunikasi dua arah dengan mengarapkan pendapat dan saran dari forum dalam mengambil keputusan. Sedangkan komunikasi informal kepala Madrasah ialah memanggil guru ke runganya untuk bercerita mengenai persoalan tertentu, dan media yang digunakan kepala Madrasah selaian secara langsung (face to face) juga melalui telepon, grup WhatsApp, maupun melalui surat. Menurut informen kepala Madrasah Tsanawiyah Al Huda Kec. Pangkalan Susu sangat terbuka dengan para guru.

2. Upaya kepala Madrasah dalam meningkatkan kinerja guru di Madrasah Tsanawiyah Al Huda Kec. Pangkalan Susu adalah dengan memperhatikan lingkungan, memberikan motivasi sehingga membuat guru merasa nyaman dalam menjalankan tugasnya, dengan tetap menjaga kedisiplinan agar terwujud kinerja yang baik dari para guru.

3. Berdasarkan hasil penelitian gaya komunikasi kepala Madrasah Tsanawiyah Al Huda Kec. Pangkalan Susu Kab. Langkat dalam meningkatkan kinerja guru menggunakan The Equalitarian Style dan The Relinguishing Style. Kedua gaya ini saling berhubungan,yang mana Equalitarian Style adanya landasan kesamaan, artinya komunikasi ini bersifat dua arah setiap orang bebas menyampaikan pendapat atau saran. Sedangkan Relinguishing Style mencerminkan kesedian menerima saran, pendapat ataupun gagasan orang lain, dari pada keinginan perintah, meskipun kepala Madrasah mempunyai hak untuk memberi perintah.

\section{DAFTAR PUSTAKA}

Ari Irwan, (2017). Pelaksanaan Komunikasi Kepala Madrasah Dalam Profesionalitas Guru di Madrasah Aliyah Negeri Langsa. Jurnal 
Journal of Education and Teaching Learning (JETL)

Volume 3, Issue 1, January 2021

Page 13-22

Armida dkk, (2018). Panduan Penulisan Skripsi Fakultas Tarbiyah dan Keguruan UIN STS Jambi

Dwi Nurina Pitasari, (2015). Pengaruh Gaya Komunikasi Pimpinan Terhadap Kinerja Pegawai di Perpustakaan Teknologi Bandung. Jurnal Vol. 3. No 2

Fahmi, (2015). Manajemen Kinerja Teori dan Aplikasi. Bandung: Alfabeta

Fitroh Amelia, (2018). Gaya Kepemimpinan Kepala Madrasah Dalam Meningkatkan Kinerja Guru MTs PSM Nitikan Plaosan Magetan. Skripsi

Gusti Ayu, dkk. Peran Komunikasi Kepemimpinan Dalam Menjaga Loyalitas Karyawan pada Titiles Denpasar. Jurnal

Handoko, (2009). Manajemen. Yogyakarta: BPFE

Idhar, (2012). Strategi Kepemimpinan Kepala Madrasah Dalam Meningktkan Kinerja Guru Pada Pembelajaran Di MAN 3 Bima. Tesis Pascasarjana UIN Alauddin

Karwati dan Priansa, (2016). Kinerja dan Profesionalisme Kepala Sekolah Membangun Sekolah yang Bermutu. Bandung: Alfabeta

Kompri, (2015). Manajemen Pendidikan 1. Bandung: Alfabeta

Mada, S, (2006). Membangun Komunikasi Efektif di Sekolah. Jurnal

Masmuh, Abdullah. (2010). Komunikasi Organisasi Dalam Perspektif Teori dan Praktek. Malang: UMM Press.

Moleong, L.J (2011). Metodelogi Penelitian Kualitatif. Bandung: Remaja Rosda Karya

Muhammad, A, (2007). Komunikasi Organisasi. Jakarta: Bumi Aksara

Mulyasa, (2013). Manajemen dan Kepemimpinan Kepala Sekolah. Jakarta: PT. Bumi Aksara

Nanang, (2000). Lamdasan Manajemen Pendidikan. Bandung: Remaja Rosdakarya

Rejeki, Diah Sri. (2011). Proses Komunikasi Antarpribadi dalam Konteks Pengembangan Pembelajaran Organisasi Perpustakaan. Tesis. Universitas Padjajaran.

Rina Nurahman, (2017). Gaya Komunikasi Pimpinan Badan Pemberdayaan Masyrakat Aceh Selatan Dalam Motivasi Semangat Kerja Pegawai. Skripsi Universitas Islam Negeri Ar-Raniry.

Sugiyono, A. (2012). Metode Penelitian Kuantitatif Kualitatif dan RED.

Bandung: Alfabet

Suryaningsih, Heni. (2009). Pengaruh Gaya Komunikasi Pimpinan Struktural Terhadap Kinerja Staf di Universitas Padjajara. Tesis. Universitas Padjajaran. 
Page 13-22

Yusnidar, (2014). Kepemimpinan Kepala Madrasah dalam Meningkatkan Kinerja Guru pada MAN Model Banda Aceh. Jurnal Didaktika Vol. XIV, No 2

Zaini, M. F., \& Syafaruddin, S. (2020). The Leadership Behavior of Madrasah Principals in Improving the Quality of Education in MAN 3 Medan. Jurnal Iqra': Kajian Ilmu Pendidikan, 5(2), 95-106. https:/ / doi.org/10.25217/ji.v5i2.649 